EESTI NSV TEADUSTE AKADEEMIA TOIMETISED. VII KÖIDE

BIOLOOGILINE SEERIA. 1958, NR. 1

ИЗВЕСТИЯ АКАДЕМИИ НАУК ЭСТОНСКОЙ ССР. ТОМ VII

СЕРНЯ ВНОЛОГИЧЕСКАЯ. 1958, № 1

\title{
ИССЛЕДОВАНИЕ ФИЛЬТРАЦИОННЫХ ЯВЛЕНИЙ В ЩЕЛЕВОМ ЛОТКЕ
}

\section{X. ПАРMACTO}

При исследовании динамикн грунтовых вод наиболее надежными являются наблюдения в полевых условиях.

Однако при изучении неустановившегося движения в условиях анизотропных грунтов полевые наблюдения не дают точной картины, так как они связаны с местными условиями, а граничные условия обычно не определены. В лабораторных же условиях возможно моделирование в разных .вариантах с заданными граничными условиями.

Теоретическое исследование неустановившейся фильтрации затруднительно, так как форма кривой депрессии в начальный момент неизвестна. Пока отсутствует и общее математическое решение для случая неустановившейся фнльтрации (даже для нзотропного грунта), так как уравнение фильтрации является нелинейным дифференциальным уравнением с частными производными второго порядка. Процесс фильтрацин в двуслойной среде, имеющий место при осушении глинистых почв, еще сложнее. Математическое решение для случая, когда кривая депрессии при фнльтрации через двуслойный грунт находится в верхнем горизонте, дано П. Ф. Полубариновой-Кочиной [ $\left.{ }^{6}\right]$. Для случая, когда кривая депрессии частично находится и в ннжнем горизонте, математического решения нет. В связи с этим для выяснения общих закономерностей целесообразно использованне лабораторных методов.

Длія лабораторного исследования фильтрации существует ряд методов, из которых важнейшими являются метод электрогидродинамической аналогии (ЭГДА) и моделирование в грунтовом и щелевом лотке. При пользовании методом ЭГДА свободная поверхность находится путем постепенного приближения, а моделирование неустановившейся фильтрации невозможно. При моделировании в щелевом лотке кривая дегрессин получается непосредственно, автоматически, и имеется возможность определить пьезометрическое давление в любой точке. С помощью красителей можно наблюдать и линии токов. Особенно удобно моделировать таким образом неустановившуюся фильтрацию. Ранее проведенные опыты хорошо совпадают с теорией $\left[{ }^{5},{ }^{7}\right]$.

Моделирование фильтрационного потока в щелевом лотке основано на аналогин между ламинарным движением жидкости в щели между пластинками н движением воды в грунте. Теорня лотка изложена В. И. Аравиным ['].

Для исследования неустановившегося движения нами был построен из стекла один лоток для моделирования установившейся и 4 лотка для моделирования неустановившейся фнльтрации в двуслойной среде, 3 лотка нмели разные соотношения коэффициентов проницаемости верхнего и нижнего слоев, условно принимаемых за пахотный и подпахотный слои, а в четвертом лотке моделировалась уменьшающаяся по глубине подпахотного горизонта проницаемость.

\section{РЕЗУЛЬТАТЫ ОПЫТОВ}

\section{Установившаяся фильтрация}

1. Для схемы, при которой весь подпахотный горизонт покрыт малым слоем воды одной и той же высоты, удельный расход определен по гидродинамической сетке в лотке (рис. 1) при $\frac{l}{T}=1,5$ 


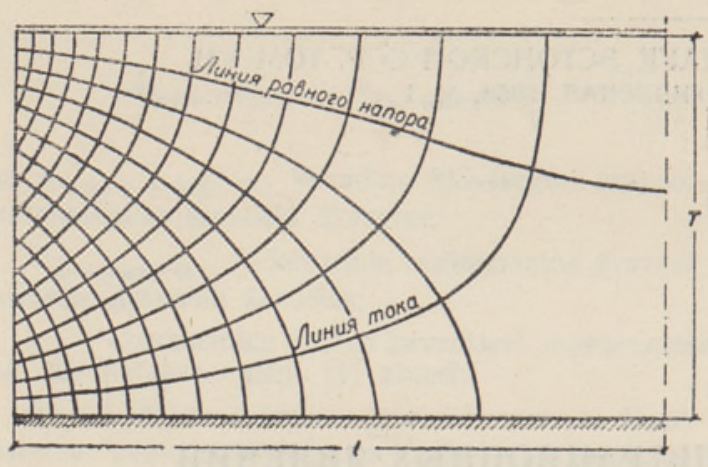

Рис. 1. Гидродинамическая сетка для случая, когда уровень грунтовых вод выше поверхности земли.

$$
q^{\prime}=0,72 k T
$$

где $k$ - коэффициент фильтрации;

$T$ - толщина фильтрующего грунта.

Теоретически получено, что при $\frac{l}{T}=2,0 \quad q^{\prime}=0,72 k T$ и при $\frac{l}{T}=\infty$ $q^{\prime}=0,74 k T\left[{ }^{4}\right]$, где $l$ - половина расстояния между дренами или канавами.

Полученные данные показывают, что результаты опытов хорошо совпадают с теоретическими значениями.

Когда подпахотный горизонт заполнен сло-

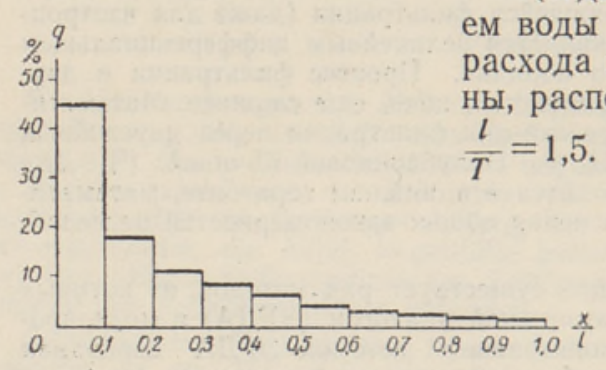

Рис. 2. Элементарные расходы в зависимости от расстояний от дрены. расхода в начальный момент поступает из зоны, расположенной вблизи дрены (рис. 2), где $\frac{l}{T}=1,5$. На рис. 2 на оси абсцисс отмечено расстояние места определения элементарного расхода от дрены в долях от половины расстояния между дренами.

Для наблюдаемых в натуре отношений $\frac{l}{T}$ расход из зоны, расположенной вблизи дрены, еще больше $[2,8]$. После образования кривой депрессии элементарный расход между двумя линиями токов из зоны, находящейся в середине между дренами, увеличивается. Это значит, что увеличивается и скорость понижения уровня грунтовых вод в этой зоне.

2. При внутреннем питании грунтовых вод, когда образована кривая депрессии, линии равных напоров не являются вертикальными, как это предполагается при использовании гидравлической теории (предположение Дюпюи). Уклон свободной поверхности жидкости также неточно соответствует градиенту напора (рис. 3 ). Исходя из этого является неточной и формула Ротэ. Однако с увеличением соотношения $\frac{l}{T}$ влияние «аномальной» части (зоны вблизи дрен и в середине междудренья) уменьшается.

\section{Неустановившаяся фильтрация}

Цель опытов заключалась в выяснении механизма работы дренажа при двуслойной среде с неустановнвшейся фильтрацией. 


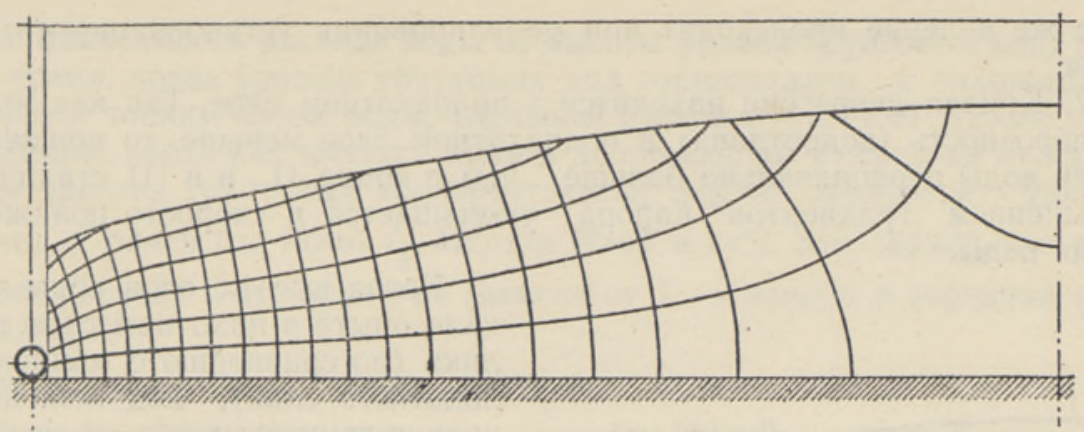

Рис. 3. Гидродинамическая сетка при внутреннем питании грунтовых вод.

Рассматривались следующие вопросы: 1) ход освобождения пахотного горизонта от воды, 2) время освобождения пахотного горизонта от воды, 3) зависимость расхода воды от уровня грунтовых вод, 4) влияние водопроницаемости засыпки дренажной траншеи на время освобождения пахотного горизонта от воды и 5) форма депрессионной кривой.

Водопроницаемость пахотного слоя при принятых размерах щелей в лотке была в 125 раз больше водопроницаемости подпахотного горизонта.

1. Ход освобождения пахотного слоя от гравитационной воды. При большой (по сравнению с мощностью пахотного слоя) высоте воды в пахотном горизонте можно проследить понижение уровня грунтовой воды в середине между дренами и разбить его на четыре стадии (рис. 4).

I. Вначале горизонтальная свободная поверхность переходит в линию депрессии. Сток происходит в пахотном и подпахотном слое прямо в засыпку. Понижение свободной поверхности в середине между дренами относительно малое. Происходит интенсивный сток из области, непосредственно прилегающей к дрене.

II. Образовалась кривая депрессии, которая находится сперва целиком в пахотном слое, а затем опускается в подпахотный слой (в дренажную траншею). Позже место пере-

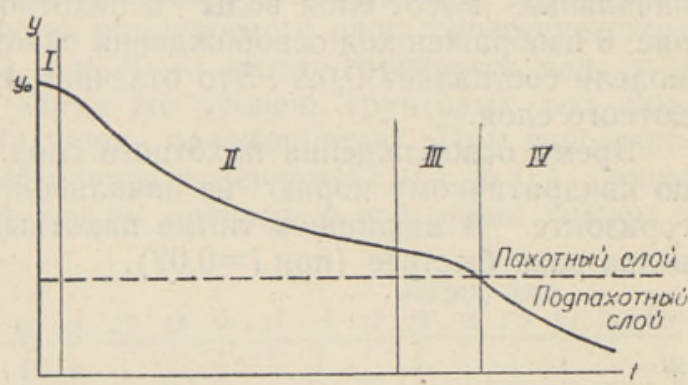

Рис. 4. Ход освобождения пахотного слоя от воды при большой высоте начального слоя воды: $t$-время от начала опыта, $y$ - высота уровня воды в середине между дренами над поверхности дрен, $y_{0}$-высота уровня воды в начале опыта. сечения кривой депрессии с под-

пахотным слоем удаляется от дренажной траншеи. Происходит сильный сток вдоль пахотного слоя. Когда точка пересечения кривой депрессии с линией, отделяющей пахотный и подпахотный слои, находится на некотором расстоянии от дренажной траншеи, приток воды к дрене происходит только через подпахотный слой. С понижением слоя воды в пахотном слое уменьшается уклон кривой депрессии, уменьшаются также сток вдоль пахотного слоя и скорость понижения уровня грунтовых вод.

III. Сток вдоль пахотного слоя практически окончен несмотря на то, что половина депрессионной кривой еще находится в пахотном слое $(\xi=0,5)$. В конце стадии увеличиваются как сток из зоны, расположенной в середине между дренами, так и скорость понижения уровня воды. 
Такое же явление происходит при моделировании установившегося движения.

IV. Кривая депрессии находится в подпахотном слое. Так как активная порозность (водоотдача) в подпахотном слое меньше, то понижение уровня воды первоначально больше, чем в конце II и в III стадий. С уменьшением градиентов напора уменьшается и скорость понижения уровня воды.

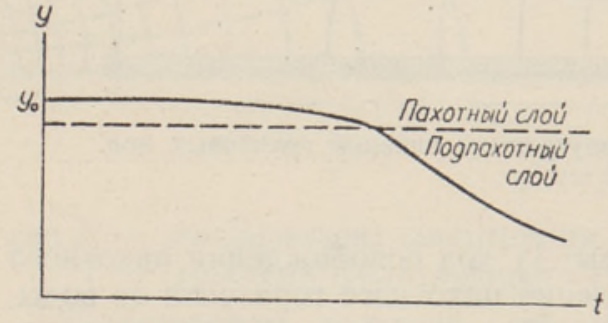

Рнс. 5. Ход освобождения пахотного слоя от воды при небольшой высоте начального слоя воды: $t$ - время от начала опыта, $y$ - высота уровня воды в середине между дренами над поверхностью дрен, $y_{0}$ - высота уровня воды в начале опыта.

Когда высота слоя воды в начале опыта в пахотном слое невелика (по сравнению с мощностью пахотного слоя), ход понижения уровня грунтовых вод происходит иначе (рис. 5). Хотя зона вблизи дрены освобождается сравнительно быстро, это не влияет на ход понижения уровня в середине между дренами, так как отсутствует сток вдоль пахотного слоя и последний освобождается от воды только через подпахотный слой. Быстрое понижение уровня воды начинается после опускания кривой депрессии в подпахотный слой.

2. Время освобождения пахотного слоя от гравитационной воды. На рис. 6 и 7 показан ход освобождения пахотного слоя в зависимости от начальных высот слоя воды в пахотном слое. Пунктирной линией на рис. 6 изображен ход освобождения пахотного слоя, когда уклон щелевой модели составляет 0,02 . Это отвечает профилированию подошвы подпахотного слоя.

Время освобождения пахотного слоя приблизительно пропорционально квадратичному корню из начальной высоты слоя воды в пахотном горизонте. В наклонном лотке пахотный слой освобождается примерно в два раза быстрее (при $i=0,02)$.

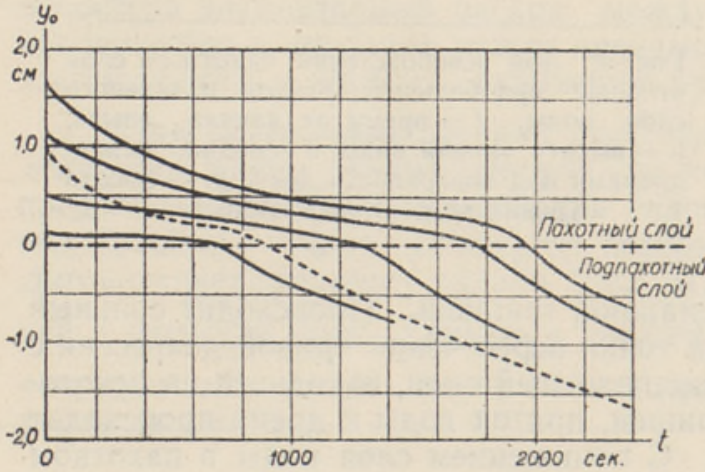

Рнс. 6. Время освобождения пахотного слоя от воды в зависимости от начальной высоты слоя воды: $t$-время освобождения пахотного слоя от воды, $y_{0}-$ начальная высота слоя воды в пахотном слое.

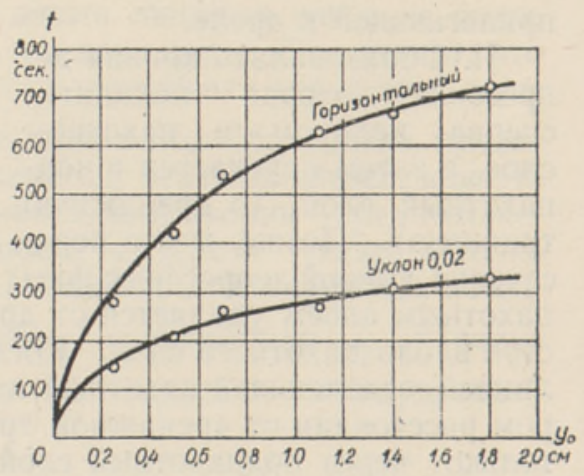

Рнс. 7. Влияние уклона подошвы пахотного слоя на время освобождения пахотного слоя от воды: $t$-время освобождения пахотного слоя от воды, $y_{0}$ - начальная высота слоя воды в пахотном слое. 
3. Зависимость расхода воды от высоты уровня грунтовых вод. В первое время, когда уровень грунтовых вод горизонтален и пахотный слой заполнен тонким слоем воды, удельный расход $q^{\prime}=0,74 k T$. После начала движения, когда уже имеется кривая депрессии, но в середине между дренами уровень грунтовых вод практически еще не понизился, удельный расход $q^{\prime}$ равен (по Ротэ) $\frac{H}{x} k H$, где $H \approx T$ и $x<l$. Это значит, что уменьшение расхода в это время не зависит от $T$ - напора в середине между дренами.

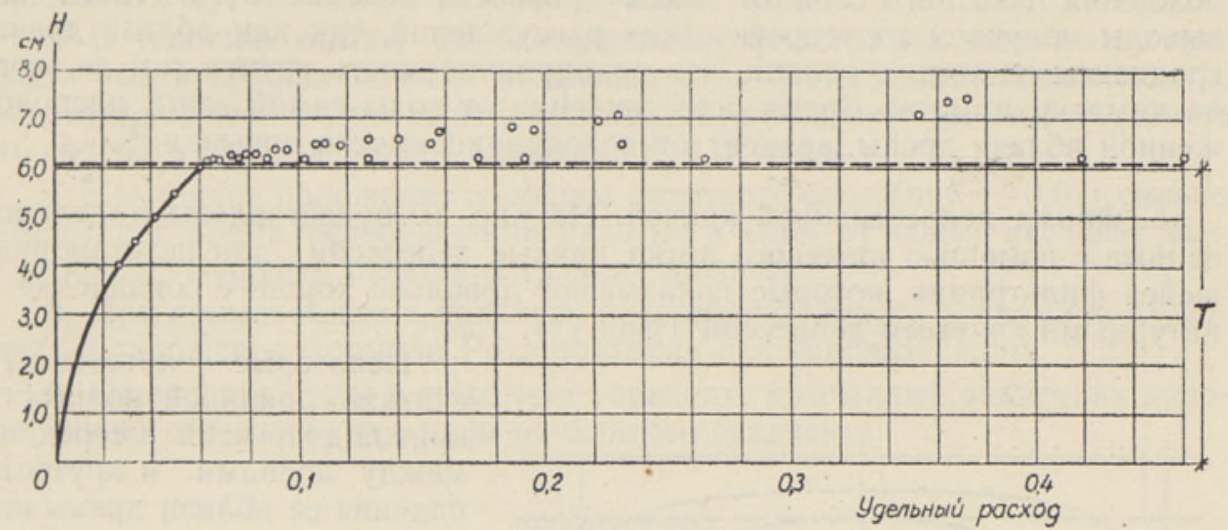

Рис. 8. Кривая расхода в слоистом грунте.

На основе ряда опытов составлена кривая расходов (рис. 8), по которой можно заметить, что в границах подпахотного слоя существует определенная зависимость $q=f(H)$, где $H$ - напор грунтовых вод, и эта зависимость параболическая. Когда же уровень грунтовых вод поднимается в пахотный слой $(H \approx T)$, точки рассеиваются. При небольшой высоте начального слоя удельный расход изменяется с 0,4 до 0,1 , причем высота уровня воды в середине между дренами в это время совсем не изменяется.

Pacxog boga

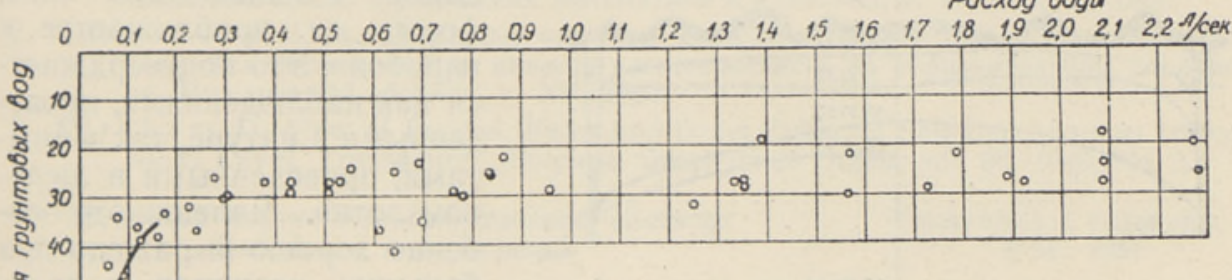

Рис. 9. Кривая расхода системы № 6 в совхозе «Рахноя» $(E=30 \mathrm{~m}, k=0,0001 \mathrm{~cm} /$ сек).

Подобное явление происходит и в натуре, что видно по рис. 9, на котором дается кривая расхода в зависимости от глубины грунтовой воды для дренажной системы № 6 в совхозе «Рахноя».

4. Влияние водопроницаемости засыпки дренажной траншеи на время освобождения пахотного слоя от воды. Для выяснения этого вопроса определено время освобождения пахотного слоя от гравитационной воды при различных начальных высотах слоев воды в пахотном горизонте и при разной водопроницаемости засыпки, а именно: 
а) водопроницаемость засыпки и пахотного слоя равны,

б) водопроницаемость засыпки примерно в 20 раз меныше водопроницаемости пахотного слоя,

в) водопроницаемость засыпки равна водопроницаемости подпахотного слоя; это значит, что она в 125 раз меныше проницаемости пахотного слоя.

Выяснено, что при данных соотношениях водопроницаемость засыпки дренажных траншей практически не оказывает влияния на время освобождения пахотного слоя от воды (разность меньше 5\%). Такие же выводы получаем из теоретических рассуждений, так как вблизи дрены градиенты настолько велики, что водопроницаемость грунта там не всегда лимитирует сток. Время освобождения от воды самой зоны, расположенной вблизи дрены, зависит от водопроницаемости засыпки [2].

5. Форма депрессионной кривой. На рис. 10 представлены моделированные с помощью щелевого лотка кривые депрессии для неустановившейся фильтрации, которые показывают довольно хорошее совпадение с натурными кривыми депрессии (рис. 11).

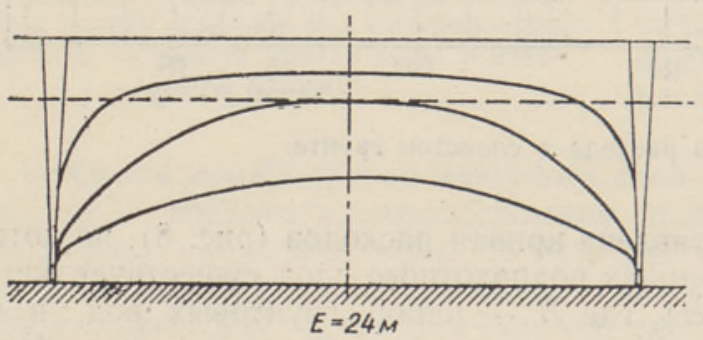

Рис. 10. Кривые депрессии в щелевом лотке.

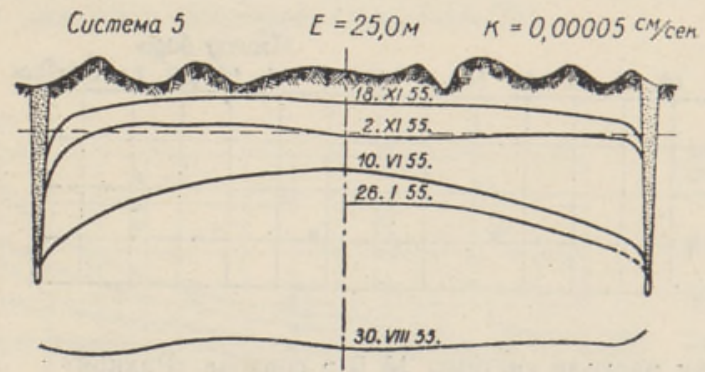

Рнс. 11. Характерные кривые депрессин на опытном участке в совхозе «Рахноя».

Некоторые авторы [ $\left.{ }^{3}\right]$ считают причиной пологости кривой депрессии в середине между дренами и крутости падения ее вблизи дрены интенсивное испарение в глинистых почвах. Но наблюдения, произведенные поздней осенью, когда испарение незначительно, показывают, что в том случае, когда кривая депрессии находится в пахотном слое, она всегда почти горизонтальна. Напротив, когда депрессионная кривая находится по всей своей длине в подпахотном слое, форма еe приближается к параболе. Это подтверджается как наблюдениями, проведенными в натуре, так и опытами, проведенными в щелевом лотке. Явление это особенно хорошо выражено при больших разницах в водопроницаемости подпахотного и пахотного слоев. Причиной пологости кривой депрессии в глинистых почвах являются:

а) двуслойной профиль, где водопроницаемость верхнего слоя во много раз больше водопроницаемости нижнего слоя,

б) увеличение плотности и уменышение водопроницаемости в нижнем слое. 


\section{Выводы}

1. Для исследования фильтрационных явлений при осушении глинистых почв, где водопроницаемость пахотного слоя во много раз больше водопроницаемости подпахотного, можно использовать щелевой лоток, так как полученные таким образом результаты (кривые расходов и депрессий) хорошо совпадают с результатами, полученными в натуре.

2. Освобождение пахотного слоя от гравитационной воды происходит в основном путем стока через подпахотный слой.

3. В условиях опыта, где коэффициент фильтрации пахотного горизонта был в 125 раз больше коэффициента фильтрации подпахотного, водопроницаемость дренажной засыпки не оказывает заметного влияния на скорость освобождения пахотного слоя от воды.

4. Наклонное положение подошвы пахотного слоя (при $i=0,02$ ) сильно уменьшает время освобождения пахотного слоя от воды, что дает возможность увеличить расстояние между дренами.

5. При применяемых.в практике расстояниях между дренами и глубинах их заложения формула Ротэ пригодна для использования.

6. Отсутствие стока в пахотном горизонте при малых значениях напора можно объяснить влиянием начального градиента.

\section{ЛИТЕРАТУРА}

1. А р в и н В. И., Основные вопросы экспериментального исследования движения грунтовых вод в щелевом лотке. Известия Научно-исследовательского института гидротехники, т. XXIII, 1938.

2. В еде р ников В. В., Теория фильтрации и ее применение в области ирригации и дренажа. М.-Л., 1939.

3. Г ей тм ан В. Г. и Пи с а рьков Х. А., Осушение сельскохозяйственных земель. M., 1955.

4. Нельсон-Скорняков Ф. Б., Фильтрация в однородной среде. Москва; 1949.

5. Полу бариннов а - К о ин а П. Я., О некоторых неустановившихся движениях грунтовых вод. Изв. АН СССР, ОТН, 1949, № 6.

6. Пол убарин в в - Кочин а П. Я., К теории неустановившихся движений в многослойной среде. Прикладная математика н механика, т. XV, вып. 4, 1951.

7. С ем ч и но в а М. М., Сравненне опытных данных с теорией для случая неустановившейся фильтрации из канала, расположенного на горизонтальном водоупоре. Инженерный сборник, т. XV, 1953.

8. Ki r k h m, D., Flow of Ponded Water into Drain Tubes in Soil Overlying an Impervions Layer. Transaction, American Geophysical Union, vol. 30, 1949, No. 3.
Эстонский научно-исследовательский институт земледелия и мелиорации
Поступила в редакцию
8 III 1957

\section{FILTRATSIOONINAHTUSTE UURIMINE PILURENNI ABIL}

\section{H. Parmasto}

\section{Resümee}

Savimaade kuivendamisel, kus künnikiht vastavalt põlluharimisvõtetele on hästi vett juhtiv, künnialune kiht aga halvasti vett juhtiv, esineb filtratsioonivool kahekihilises keskkonnas. Kuna nimetatud juhul puudub üldine matemaatiline lahendus ja kuna pole vōimalik otseseid vaatlusi looduses alati teha, uuriti neid küsimusi pilurennis modelleerimise abil. Modelleerimise tulemused (äravoolukôverad ja depressioonijooned) ühtivad looduses tehtud vaatluste andmetega, 
Modelleerimisandmetest selgus järgmist:

1) Künnikihi vabanemine veest toimub peamiselt äravoolu teel läbi künnialuse kihi.

2) Katsetes, kus künnikihi filtratsioonikoefitsient oli 125 korda suurem aluskihi filtratsioonikoefitsiendist, ei avalda dreenikaeviku täitematerjali veejuhtivus (antud vahekordade juures) praktiliselt mingit mōju ajale, mille vältel künnikiht vabaneb veest.

3) Kui künni aluskiht on profileeritud ja omab langu 0,02 , siis toimub künnikihi vabanemine veest kaks korda kiiremini. Künni aluskihi profileerimine vōimaldab suurendada dreenide vahelaiusi.

4) Praktikas kasutatavate dreenide vahelaiuste ja sügavuste arvutamiseks, kui dreenid asuvad vett mitte läbilaskval kihil, on kehtiv Rothe valem.

5) Et voolamine piki künnikihti lōpeb, kui suur osa depressioonijoonest asub veel künnikihis, tõestab, et põhjavee voolamiseks on vajalik nn. alggradient. Eesti Maaviljeluse ja Maaparanduse
Teadusliku Uurimise Instituut
Saabus toimetusse

8. III 1957

\section{RESEARCH ON FILTRATION PHENOMENA BY MEANS OF CAPILLARY FLUMES}

\section{H. Parmasto}

\section{Summary}

At the draining of loamy soils where, owing to cultivating methods, the cultivating horizon conducts water to a sufficient extent, and the subsoil, on the other hand, conducts water insufficiently, the filtration flow is conducted in a 2-layer medium. As there is no general mathematical solution of the problem and it is not always possible to carry out an observation in natural surroundings, the problem was investigated on a model of a capillary flume. The data of the experiments (the drainage and depression curves) coincide with the results attained in nature.

The data of the research proved, as follows: soil.

1. The drainage of the topsoil takes place by the water running off through the sub-

2. At the tests, where the filtration coefficient of the topsoil exceeds by 125 times that of the subsoil, the conductivity of water of the filling material of drainage ditches does not practically affect the duration of the draining process of the topsoil.

3 . When the subsoil is profiled and has a slope of 0.02 , the draining of the topsoil is effected twice as rapidly. The profiling of the subsoil enables to increase the distance between the drains.

4. The distance between the drains and the depth of the trenches, used in practice, may be computed with the help of Rothe's formula, if the drains are situated in a watertight stratum.

5. An initial gradient ise necessary for the drainage of depth water, which is proved by the fact that the flow along the topsoil stops when a large part of the depression line is still in the cultivating horizon.

The Estonian Scientific Research Institute of Agriculture and Melioration

Received

March 8, 1957 